\begin{tabular}{|c|l|}
\hline Title & $\begin{array}{l}\text { Comparisons of Host Specificity in Feather Louse Genera (Insecta: Phthiraptera: Philopteridae) Parasitizing Gulls } \\
\text { (A ves: Laridae:Larus) }\end{array}$ \\
\hline Author(s) & Yamagishi, Ayaka; Y ao, Izumi; Johnson, Kevin P.; Y oshizawa, Kazunori \\
\hline Citation & $\begin{array}{l}\text { Zoological Science, 31(6), 383 389 } \\
\text { https://doi.org/L0.2108/2s130263 }\end{array}$ \\
\hline Issue Date & 201406 \\
\hline Doc URL & http://hdl.handle.net/2115/59447 \\
\hline Type & article \\
\hline File Information & 2014Zool Sci Gull Louse.pdf \\
\hline
\end{tabular}

Instructions for use 


\section{Comparisons of Host Specificity in Feather Louse Genera (Insecta: Phthiraptera: Philopteridae) Parasitizing Gulls (Aves: Laridae: Larus)}

Author(s): Ayaka Yamagishi, Izumi Yao, Kevin P. Johnson and Kazunori Yoshizawa

Source: Zoological Science, 31(6):383-389. 2014.

Published By: Zoological Society of Japan

DOI: http://dx.doi.org/10.2108/zs130263

URL: http://www.bioone.org/doi/full/10.2108/zs130263

BioOne (www.bioone.org) is a nonprofit, online aggregation of core research in the biological, ecological, and environmental sciences. BioOne provides a sustainable online platform for over 170 journals and books published by nonprofit societies, associations, museums, institutions, and presses.

Your use of this PDF, the BioOne Web site, and all posted and associated content indicates your acceptance of BioOne's Terms of Use, available at www.bioone.org/page/terms_of_use.

Usage of BioOne content is strictly limited to personal, educational, and non-commercial use. Commercial inquiries or rights and permissions requests should be directed to the individual publisher as copyright holder. 


\title{
Comparisons of Host Specificity in Feather Louse Genera (Insecta: Phthiraptera: Philopteridae) Parasitizing Gulls (Aves: Laridae: Larus)
}

\author{
Ayaka Yamagishi ${ }^{1}$, Izumi Yao', Kevin P. Johnson ${ }^{2}$, \\ and Kazunori Yoshizawa ${ }^{1 *}$ \\ ${ }^{1}$ Systematic Entomology, School of Agriculture, Hokkaido University, Sapporo 060-8589, Japan \\ ${ }^{2}$ Illinois Natural History Survey, University of Illinois, Champaign, IL 61820, USA
}

\begin{abstract}
Data from gene sequences and morphological structures were collected for the gull feather lice, Saemundssonia lari, Quadraceps punctatus, and Q. ornatus, parasitizing Larus crassirostris and $L$. schistisagus. Saemundssonia lari was collected from both gull species, and no detectable morphological and genetic differences were found between lice collected from the two different hosts. In contrast, Q. punctatus was only collected from $L$. crassirostris, whereas $Q$. ornatus was only collected from $L$. schistisagus. The two Quadraceps species were genetically highly divergent, and body-size differences corresponding to the gull's body size (Harrison's rule) were also detected between them. Both Quadraceps species were collected from the interbarb of the remex or rectrix, and a match in body size between the louse and the interbarb space may be important in escape from host preening defenses. In contrast, Saemundssonia is a head louse, inhabiting the finer feathers of the head and neck, which the bird cannot preen. A close match to host body size may be less important for lice in the head microhabitat. The differences in the pattern of host-specificity between Saemundssonia and Quadraceps on the two focal host species of this study were probably due to their different microhabitat preferences. More broadly, comparisons of the gene sequences of S. lari and Q. punctatus to those from other gull hosts showed that genetically almost undifferentiated populations of both species were distributed on wide range of gull species. Frequent interspecific hybridization of gulls is one possible factor that may allow these lice to maintain gene flow across multiple host species.
\end{abstract}

Key words: Saemundssonia, Quadraceps, Harrison's rule, host switch, parasitic lice

\section{INTRODUCTION}

Parasitic lice (Psocodea: Phthiraptera) are obligate parasites of mammals and birds and spend their entire lifecycle on their hosts. Their external structures (e.g., flattened body, short legs, absence of wings) are highly specialized to an ectoparasitic lifestyle, and their mobility is extremely limited (Johnson and Clayton, 2003). Usually, lice transmit to a new host individual only via direct contact between the hosts, such as during copulation (Hillgarth, 1996) or parental care (Clayton and Tompkins, 1994). Due to these constraints, parasitic lice frequently show strong host specificity, and many species of lice are restricted to single genus or species of host (e.g., Marshall, 1981). This strong host specificity makes the lice an ideal model system for studying the host-parasite coevolution and co-speciation (Johnson and Clayton, 2003).

This high host specificity notwithstanding, some lice

\footnotetext{
* Corresponding author. Tel. : :+81-11-706-2424;

Fax : +81-11-706-4939;

E-mail: psocid@ res.agr.hokudai.ac.jp
}

Supplemental material for this article is available online. doi:10.2108/zs130263 show low host specificity and parasitize a wide range of host species (Price et al., 2003). It is widely thought that a wide range of host species is made possible by some factors other than direct contact between hosts. For example, it is well known that the hippoboscid flies frequently transmit lice between different host bird species (phoresis; Keirans, 1975). In such cases, genetic structure of a louse species is known to reflect biogeography rather than the host distribution, probably restricted by the distributional range of hippoboscid flies (Johnson et al., 2002; Weckstein, 2004). However, even if lice successfully transmit to a different host species via phoresis or other means, morphological mismatch between host and louse may prohibit colonization of the new host species by the lice. For example, the wing lice of birds escape from host preening defenses by inserting themselves between the barbs of the wing feathers. One study found that the body width of the wing lice from pigeons and doves is strongly correlated with host body size, which dictates the width of the feather interbarb space (Johnson et al., 2005). A mismatch between louse body width and the host's interbarb space prevents the louse from escaping host preening, and makes it difficult to colonize host species that differ in body size from the native host.

Even in species of lice with a wide host range, molecular 
analyses sometimes reveal significant genetic divergence between lice on different host species. For example, species of both body and wing lice that parasitize different species of doves show considerable population structure between different host species (Johnson et al., 2002). A similar pattern has also been identified in the louse genus Lunaceps that parasitizes shore birds (Gustafsson and Olsson, 2012). Deep genetic divergence within a louse species on a single host species, but in different geographic locations, has also been identified (Mizukoshi et al., 2012). These examples clearly show that it is sometimes inappropriate to evaluate the host-range of a louse species based on morphological information alone, which has been utilized for species-level taxonomy of lice.

Saemundssonia lari is one louse species with a very wide host range, recorded from 36 species across six genera of Laridae (gulls and their relatives) (Price et al., 2003). This species is of the head louse ecomorph (Johnson et al., 2012), possessing a triangular head and rounded body (Fig. $1 \mathrm{~A})$, and living in the head and neck regions of the bird using its mandibles to grip feather barbs. Gulls are also parasitized by a closely related genus, Quadraceps (Cruickshank et al., 2001; Smith et al., 2004; Price et al., 2003). This genus is broadly recognized as a generalist (Johnson et al., 2012). However, species of the genus parasitizing gulls have an elongated head and body (Fig. 1B, C), and they insert into the interbarb spaces of the flight feathers on the wing in a similar way to wing lice that use this behavior to escape preening (Clayton et al., 2003). Therefore, the species treated here exhibit the same escape behavior as the wing louse ecomorph found on other groups of birds. In general, species of Quadraceps show a much higher degree of host specificity than those of Saemundssonia. Four species, subdivided into many subspecies, of Quadraceps have been recorded from the gull genus Larus (Price et al., 2003).

In this study, we compare the morphological and genetic structures of Saemundssonia and Quadraceps collected from two species of gulls breeding in Japan: black-tailed gull (Larus crassirostris) and slaty-backed gull (Larus schistisagus). The former is smaller (ca. $47 \mathrm{~cm}$ ) than the latter (ca. $64 \mathrm{~cm}$ ) in body length, and both gulls are parasitized by Saemundssonia lari. However for Quadraceps, the black-tailed gull is host only to Quadraceps punctatus (also known to parasitize 26 other Larus species) whereas the slaty-backed gull is host only to $Q$. ornatus (also known to parasitize six other Larus species). In this study we address (1) are there any hidden morphological or genetic differences in $S$. lari parasitizing different host species and, if not, (2) what causes the difference in host specificity between the two closely related louse genera using different microhabitats of the same two host species.

\section{MATERIALS AND METHODS}

All samples were collected at Teuri Island, an island located west to northern Hokkaido. This island is isolated around $28 \mathrm{~km}$ from the mainland Hokkaido, and its circumference is about $3 \mathrm{~km}$.
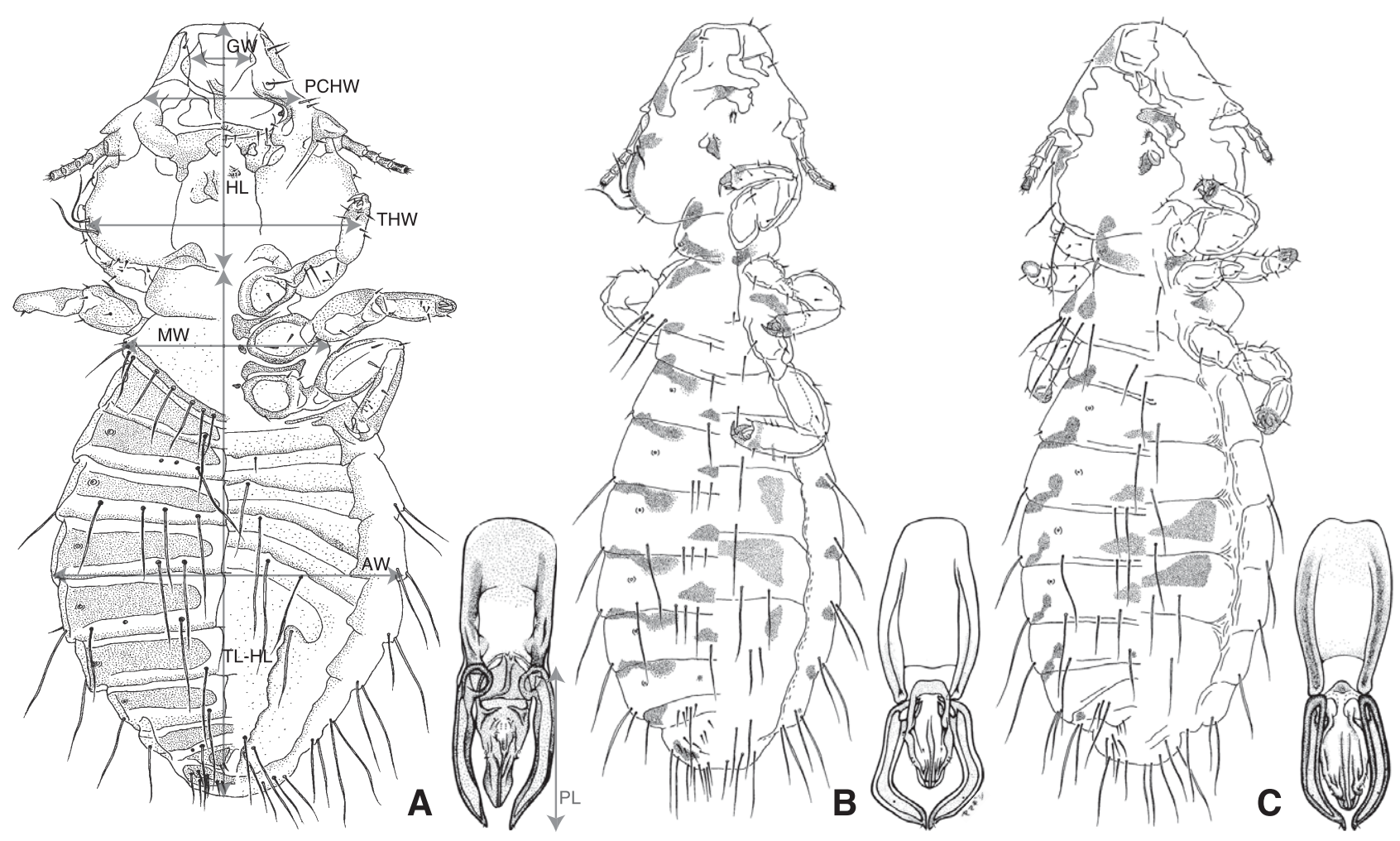

Fig. 1. Habitus (left) and male genitalia (right) of (A) Saemundssonia lari, (B) Quadraceps punctatus, (C) Quadraceps ornatus. In the habitus figures, dorsal (left) and ventral (right) structures are shown. Arrows in (A) indicate measurements used for morphological analyses. Abbreviations: $\mathrm{PCHW}=$ precornal head width; $\mathrm{THW}=$ temporal head width; $\mathrm{AW}=$ abdominal width (5th segment); $\mathrm{HL}=\mathrm{head}$ length; $\mathrm{TL}-\mathrm{HL}=$ total length minus head length; $P L=$ paramere length. 
Both black-tailed and slaty-backed gulls breed on this small island. Both head (Saemundssonia) and wing lice (Quadraceps) were collected from living and dead birds under permits from the Agency for
Cultural Affairs and from Ministry of the Environment. Louse specimens were searched for by eye and picked up using a forceps. Lice were killed and preserved in $99.5 \%$ ethanol. For Saemundssonia
(0) ex. Larus crassirostris

ex. Larus schistisagus bootstrap values (MP/ML)

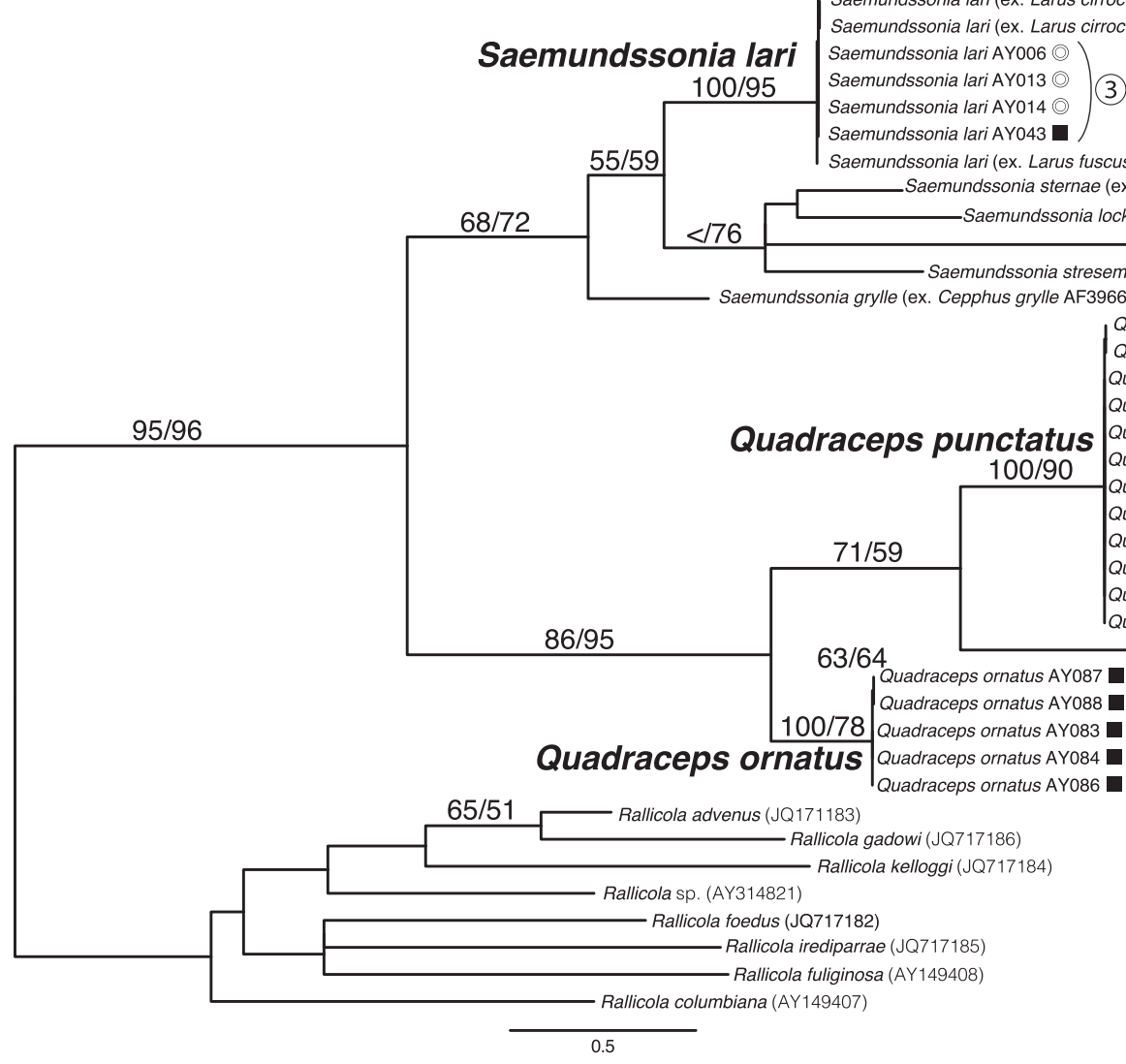

Fig. 2. Maximum likelihood tree of gull feather lice, Saemundssonia lari, Quadraceps punctatus and Q. ornatus. Some other species of Saemundssonia and Quadraceps were also included, and tree was rooted with Ralicola. Branch lengths are proportional to substitutions per site. Numbers associated with each branch indicate MP and ML bootstrap values. Circled numbers on S. lari indicate the haplotype ID mentioned in the text. 
lari, 16 males and 16 females collected from five different blacktailed gulls, and 10 males and 14 females collected from 11 slatybacked gulls. For Quadraceps, eight males and seven females of Q. punctatus were collected from four different black-tailed gulls, and seven males and nine females were collected from six slatybacked gulls.

Partial sequences (334 bp) of the mitochondrial cytochrome oxidase subunit I gene (COI) were amplified and sequenced using primer pairs L6625 + H7005 (Hafner et al., 1994). Protocols for total DNA extraction, PCR, sequencing and alignment followed Yoshizawa (2004). However, initial PCRs only provided faint amplification for $Q$. ornatus. Therefore, the PCR product was cloned prior to sequencing using pGemT Easy Vector system (Promega, Madison, Wisconsin) following manufacture protocols. GenBank Accession Numbers for the presently obtained sequences are AB909115AB909120. Voucher specimens are stored in Hokkaido University Insect Collection. Sequences for the outgroups (Rallicola) and some Saemundssonia spp. and Quadraceps spp., including those of $S$. lari and $Q$. punctatus from other host gulls, were also obtained from GenBank.

Phylogenetic analyses were conducted under maximum parsimony and maximum likelihood criteria using PAUP* 4.0 b10 (Swofford, 2002). For MP analysis, all characters were equally weighted, and heuristic searches were conducted with 100 random starting trees and TBR branch swapping. For ML analysis, a single heuristic search with TBR branch swapping was performed using a NJ tree as a starting tree. The best-fit substitution model for $M L$ analysis was estimated by hierarchical Likelihood Ratio Test as implemented in jModelTest 2.1.1 (Darriba et al., 2012), and the HKY+G model was selected. Detailed parameters of the substitution model are described in the data matrix available as an Online Supplementary Data. Bootstrap support values were calculated from 100 pseudoreplicates under both MP and ML using PAUP*. Parameter settings for bootstrap analyses were identical to those adopted for MP and $\mathrm{ML}$ tree estimation.

The voucher specimens from the DNA extraction were used for morphological examination. The cleared exoskeleton was mounted on a HS slide (Shirayama et al., 1993) with Euparal. Examination was conducted with an Olympus BX40 light microscope, and the lengths of precornal head width, temporal head width, metathoracic width, abdominal width (5th segment), head length, total body length minus head length, groove width, and paramere length (a part of male genitalia: Fig. 1A) were measured (Fig. 1). Because male genital structures of two Quadraceps species differed morphologically (Fig. 1B, C), and the purpose of the paramere measurements for Saemundssonia was to determine potentially hidden morphological differences between host races, paramere length was only measured for Saemundssonia. Statistical analysis (t-test) was conducted using JMP 9.1 (SAS, 2011).

\section{RESULTS}

\section{Molecular analyses}

From Saemundssonia lari collected in Teuri Island, three haplotypes were detected, and the maximum uncorrected $p$-difference between them is only $0.6 \%$ (Fig. 2). All haplotypes clustered into a single clade, and, except for haplotype 2 unique to the slaty-backed gull $(n=4)$, all other haplotypes were present in lice from both gull species. Four sequences of $S$. lari collected from other gull species and downloaded from GenBank also clustered closely with the S. lari sequences obtained from Teuri Island. In particular, the sequences obtained from $S$. lari parasitizing herring gull (L. argentatus: Europe) and kelp gull ( $L$. dominicanus: South Hemisphere) showed completely identical sequences with the haplotype 1 of $S$. lari from Teuri Island (Fig. 2).
Even S. lari obtained from geographically distant gull species, gray-headed gulls ( $L$. cirrocephalus: Africa and South America) and lesser black-backed gull (L. fuscus: Europe), showed at a maximum only $0.9 \%$ sequence divergence from those of Teuri Island.

The two species of Quadraceps were host specific, at least within Teuri Island (Fig. 2). They are genetically highly divergent at about $22 \%$ uncorrected sequence divergence. Each species composed a clade with either a single haplotype (Q. punctatus) or two haplotypes with extremely low genetic divergence (0.3\%: Q. ornatus). Intraspecific sequence difference within Q. punctatus was low (0-1.00\%), even when including the sequences from the species on other gull hosts (i.e. $Q$. punctuatus from $L$. cirrocephalus from Africa and South America, L. dominicanus from the South Hemisphere, and L. californicus from western North America).

\section{Morphological analyses}

Significant differences in body size between males and females were detected for all species, and, in all cases, females were about $20 \%$ larger than males (Tables 2, 3).

Saemundssonia collected from different species showed no significant difference in most measurements, including groove width (a functionally relevant character used in the process of attaching to feather barbs) and paramere length (a male genitalic character) (Table 1). However, significant differences were detected in abdominal width and total body length minus head length of females (Table 1). The two Quadraceps species from the two gull species were significantly different in many features, including genital structure (Fig. 1B, C), such that their independent species status can be confirmed based on morphology alone. Significant differences existed between the two

Table 1. Measurements of Saemundssonia lari collected from two gull species.

\begin{tabular}{lccc}
\hline & from L. crassirostris & from L. schistisagus & \\
\cline { 2 - 3 } & $\begin{array}{c}n=16 \text { each } \\
\text { (male, female) }\end{array}$ & $\begin{array}{c}n=10 \text { (male), } \\
\text { P (female) }\end{array}$ & \\
\hline PCHW-male & $0.3581 \pm 0.0091$ & $0.3580 \pm 0.0244$ & 0.9852 \\
PCHW-female & $0.3963 \pm 0.0152$ & $0.3900 \pm 0.0180$ & 0.9187 \\
THW-male & $0.5831 \pm 0.0135$ & $0.5830 \pm 0.0157$ & 0.9830 \\
THW-female & $0.5606 \pm 0.0112$ & $0.6479 \pm 0.0239$ & 0.6818 \\
MW-male & $0.4619 \pm 0.0138$ & $0.4450 \pm 0.0344$ & 0.0902 \\
MW-female & $0.5125 \pm 0.0148$ & $0.5000 \pm 0.0332$ & 0.1851 \\
AW-male & $0.8150 \pm 0.0239$ & $0.7830 \pm 0.0881$ & 0.1782 \\
AW-female & $0.9667 \pm 0.0305$ & $0.9150 \pm 0.0720$ & $0.0171^{*}$ \\
HL-male & $0.5506 \pm 0.0152$ & $0.5450 \pm 0.0165$ & 0.3840 \\
HL-female & $0.5875 \pm 0.0161$ & $0.5867 \pm 0.0164$ & 0.8934 \\
TL-HL-male & $1.2111 \pm 0.0385$ & $1.1790 \pm 0.0814$ & 0.1921 \\
TL-HL-female & $1.4813 \pm 0.0427$ & $1.3817 \pm 0.1284$ & $0.0073^{* *}$ \\
GW-male & $0.1272 \pm 0.0066$ & $0.1240 \pm 0.0057$ & 0.2182 \\
GW-female & $0.1331 \pm 0.0070$ & $0.1329 \pm 0.0099$ & 0.9321 \\
PL-male & $0.2900 \pm 0.0035$ & $0.2910 \pm 0.0044$ & 0.8606 \\
\hline
\end{tabular}

Abbreviations: $\mathrm{PCHW}=$ precornal head width; $\mathrm{THW}=$ temporal head width; $\mathrm{MW}=$ metathoracic width; $\mathrm{AW}=$ abdominal width (5th segment); $H L=$ head length; $T L-H L=$ total length minus head length; $\mathrm{PL}=$ paramere length. Asterisks indicate significance at $5 \%\left(^{*}\right)$ or $1 \%\left(^{* *}\right)$. 
Table 2. Measurements of two Quadraceps species collected from two gull species.

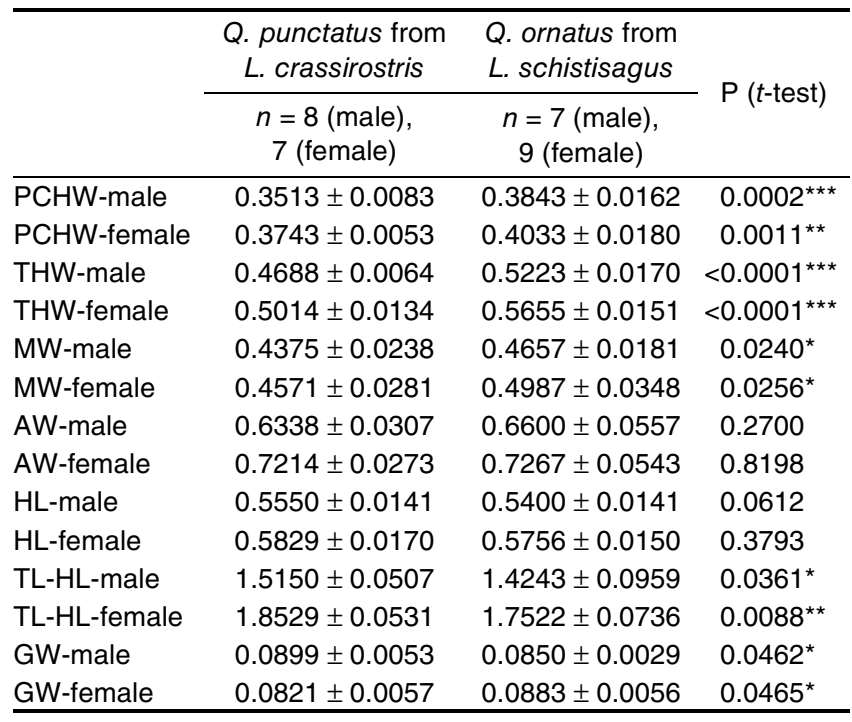

Abbreviations: $\mathrm{PCHW}=$ precornal head width; $\mathrm{THW}=$ temporal head width; $M W=$ metathoracic width; $A W=$ abdominal width (5th segment); $\mathrm{HL}=$ head length; $\mathrm{TL}-\mathrm{HL}=$ total length minus head length. Asterisks indicate significance at $5 \%\left({ }^{*}\right), 1 \%\left({ }^{* \star}\right)$ or $0.1 \%$ $\left({ }^{\star \star \star}\right)$.

Quadraceps species in the precornal head width, temporal head width, metathoracic width, and total body length minus head length, whereas no significant differences were detected in head length, and abdominal width (Table 2). Measurements showing significant differences were always larger in $Q$. ornatus, which occurs on the larger host $(L$. schistisagus), except that total body length minus head length showed the opposite trend (Table 2).

\section{DISCUSSION}

Genetic analysis indicates that Saemundssonia lari collected from two host gulls breeding on Teuri Island represent a single species with low genetic divergence. Although significant differences were identified in the abdominal width and length of female $S$. lari collected from two host gulls, the abdomen has wide membranous regions (Fig. 1A) and thus its shape can be altered easily by extrinsic factors, such as egg maturation or artifacts during slide preparations. As far as the heavily sclerotized structures are concerned, no significant morphological difference was identified between the lice from different host species. Therefore, morphological evidence also suggests that populations of these lice on the two different host species are conspecific. In contrast, the Quadraceps on the two gulls breeding on Teuri Island are clearly different species based on both morphological and molecular evidence. These results indicate that two closely related louse genera parasitizing two gull species breeding on the same island differ dramatically in their patterns in host specificity.

All Quadraceps examined in the present study were collected from the interbarb spaces of the remex or rectrix (i.e. flight feathers), whereas $S$. lari were collected from the downy part of the head and neck regions. Therefore, although Johnson et al. (2012) classified the genus Quadraceps as generalist (lice with no specific microhabitat preference on the host's body), at least the two Quadraceps species examined here can be regarded as wing lice. That is, they exhibit the same escape behavior that other wing lice use to avoid preening (Clayton et al., 2003). Saemundssonia can be confidently classified as the head louse, as also suggested by Johnson et al. (2012). These microhabitat differences are likely to be the largest factor influencing the difference in patterns of host specificity of the two louse genera parasitizing these two gull species on Teuri Island. Wing lice escape from host's preening by inserting their body between the interbarb space of the flight feathers. Any mismatch between the width of the louse and the feather interbarb space thus increases the risk of being preened off the host (Clayton et al., 2003; Bush and Clayton, 2006). In the case of the Quadraceps species examined here, lice on different host gulls show significantly different body widths, and the louse on the larger host exhibited a larger body size (Table 2), showing good correspondence between host and parasite body size. Although the abdominal length shows the opposite trend (larger in the louse on the smaller host), different from the body width, body length is less likely to cause a mismatch between louse body size and feather interbarb space, as lice insert with their central body axis parallel to the feather barbs. A correlation between host and parasite body size, generally known as Harrison's rule (Harrison, 1915; Johnson et al., 2005), probably prevents parasites from shifting to a new host with a greatly different body size. In contrast, Harrison's rule has not been detected in body lice, which burrow in feather down (Johnson et al., 2005). This also agrees with the present observation, because $S$. lari inhabit the downy parts of the bird's head and neck feathers, and no morphological difference was detected between $S$. lari collected from two gull species. However, it should also be noted that Timmermann (1951) recognized head size variation of $S$. lari roughly following Harrison's rule when host size is smaller than $L$. canus (wing length ca. $36 \mathrm{~cm}$ ), although the comparisons were not subjected to statistical tests.

The other question is what mechanisms can homogenize populations of $S$. lari parasitizing different gull species. Generally, lice transmit to a new host individual only via direct contact of host animals, such as breeding and mating, whereas interspecific direct contact between different host species is limited. Phoresis mediated by the hippoboscid flies is a well-known factor that frequently causes hostswitching of bird lice. However, no species of hippoboscid fly has been recorded from the Japanese gulls (Maa, 1969; Keirans, 1975) and thus phoresis is an unlikely mechanism. Teuri Island is utilized as a breeding site for many seabirds (including rhinoceros auklet, Japanese cormorant and so on), and their density on the island is also very high. Slatybacked gulls sometimes prey on chicks of black-tailed gulls (Watanuki, 1988). This probably provides frequent direct contact between different host species and a possible dispersal opportunity for lice. This may include not only dispersal from smaller to larger gulls, but also larger to smaller because the adults of smaller gulls will attack predatory gulls. Host-size differences probably do not prevent establishment of the head louse genus Saemundssonia (Johnson et al., 2005), but a mismatch between the louse body size 
and the feather interbarb probably prevent establishment of the wing louse genus Quadraceps on a novel host (Bush and Clayton, 2006). This local factor may also extend different breeding sites.

Several other factors may also enable lice to disperse between different species of gulls when host individuals contact each other during the breeding season. These include encounters during fishing frenzies, territorial fights, and theft of nesting material. Hybridization between gull species may also be lead to dispersal of lice between species, and such hybrids are known between many different species of gulls. For example, the white-headed gull species-group consists of 18 species, including slaty-backed gull, and different species hybridize quite frequently (Liebers et al., 2004; Olsen and Larsson, 2004; Pons et al., 2005). Although the distributional range of slaty-backed gull is restricted to Japan and neighboring regions, some gulls in the species-group show very wide distributional ranges (Olsen and Larsson, 2004). For example, hybridizing pairs of slaty-backed gull and glaucous-winged gull ( $L$. glaucescens) have been observed in Rishiri and Rebun Islands, located only ca. $75 \mathrm{~km}$ north of Teuri Is. (Kosugi, 2003; Kazama et al., 2011). The distribution of the glaucous-winged gull includes both Asia and North America, where it overlaps with a different suite of gull species. It is likely that such widely distributed gulls spread their lice widely and facilitate mixing of louse populations even between geographically distant host species.

Although these dispersal opportunities occur locally, worldwide, S. lari only shows at most $0.9 \%$ sequence difference, even between individuals collected from phylogenetically distant host species (Pons et al., 2005) whose geographic ranges are also very separated (e.g., Japan and Africa, South America). Quadraceps punctatus also shows low genetic divergences within the species, even though louse samples were from widely separated host gulls. Widespread gull species in combination with gull migration may facilitate a more global homogenization of louse populations. During winter, many species of gulls roost together in large flocks. These communal winter roosts include species of gulls that do not normally overlap during the breeding season. Ongoing gene flow of Saemundssonia among many widely distributed hosts is probably possible. However, a mismatch between parasite and host body sized likely prevents Quadraceps from establishing across such a wide range of host species. Interestingly, the host species of $Q$. punctatus examined here are mostly smaller gulls but also include a larger one ( $L$. dominicanus: about the same size as slaty-backed gull). Transmission of small lice to larger host may not prevent louse survival over shorter timescales (Bush and Clayton, 2006). It is also possible that the population of $Q$. punctuatus on $L$. argentatus is transient but, according to Timmermann (1971), Q. punctatus is quite frequently found on $L$. argentatus, as well as $Q$. ornatus. Because a single host individual rarely host two species of lice, Timmermann (1971) argued that different populations of a host species host different species of Quadraceps, and distributional ranges of Quadraceps species are rather restricted by climates than host species. Further morphological and genetic analyses of Quadraceps collected from much wider range of gull species are needed to uncover the factors which allow/ prevent dispersal and establishment of gull wing lice.

\section{ACKNOWLEDGMENTS}

We thank Y. Watanuki for allowing to collect lice in his field. We thank two anonymous reviewers for detailed comments on the manuscript. AY thanks members of Marine Ecology Laboratory, Hokkaido University and also people of Teuri Island for help in the field and T. Kanbe for help in experiments. KY thanks S. Hikosaka and R. Tomisawa for help in the field. This study was conducted as AY's Master Degree project under the supervision by KY, and was supported in part by JSPS Research Grants-in-Aid (18770058 and 21770083) to $\mathrm{KY}$.

\section{REFERENCES}

Bush SE, Clayton DH (2006) The role of body size in host specificity: reciprocal transfer experiments with feather lice. Evolution 60: 2158-2167

Clayton DH, Tompkins DM (1994) Ectoparasite virulence is linked to mode of transmission. Proc R Soc Lond B 256: 211-217

Clayton DH, Bush SE, Goates BM, Johnson KP (2003) Host defence reinforces host-parasite cospeciation. Proc Natl Acad Sci USA 100: 15694-15699

Cruickshank RH, Johnson KP, Smith VS, Adams RJ, Clayton DH, Page RDM (2001) Phylogenetic analysis of partial sequences of elongation factor 1alpha identifies major groups of lice (Insecta: Phthiraptera) Mol Phylogenet Evol 19: 202-215

Darriba D, Taboada GL, Doallo R, Posada D (2012) jModelTest 2 : more models, new heuristics and parallel computing. Nature Methods 9: 772

Gustafsson DR, Olsson U (2012) Flyway homogenisation or differentiation? Insights from the phylogeny of the sandpiper (Charadriiformes: Scolopacidae: Calidrinae) wing louse genus Lunaceps (Phthiraptera: Ischnocera). Internat J Parasitol 42: 93-102

Hafner MS, Sudman PD, Villablanca FX, Spradlling TA, Demastes JW, Nadler SA (1994) Disparate rates of molecular evolution in cospeciating hosts and parasites. Science 265: 1087-1090

Harrison L (1915) Mallophaga from Apteryx, and their significance; with a note on the genus Rallicola. Parasitology 8: 88-100

Hillgarth N (1996) Ectoparasite transfer during mating in ring-necked pheasants Phasianus colchicus. J Avian Biol 27: 260-262

Johnson KP, Clayton DH (2003) The biology, ecology, and evolution of chewing lice. In "The Chewing Lice: World Checklist and Biological Overview" Ed by RD Price, RA Hellenthal, RL Palma, KP Johnson, CH Clayton, Illinois Natural History Survey Special Publication 24, Champaign, pp 449-476

Johnson KP, Williams BL, Drown DM, Adams RJ, Clayton DH (2002) The population genetics of host specificity: genetic differentiation in dove lice (Insecta: Phthiraptera). Mol Ecol 11: 25-38

Johnson KP, Bush SE, Clayton DH (2005) Correlated evolution of host and parasite body size: tests of Harrison's rule using birds and lice. Evolution 59: 1744-1753

Johnson KP, Shreve SM, Smith VS (2012) Repeated adoptive divergence of microhabitat specialization in avian feather lice. BMC Biol 10: 52

Kazama K, Hirata K, Sato M (2011) Observations of a hybridizing pair of Slaty-backed Gull and Glaucous-winged Gull, on Rishiri Island, Hokkaido, Japan. Jpn J Ornithol 60: 241-245

Keirans JE (1975) A review of the phoretic relationship between Mallophaga (Phthiraptera: Insecta) and Hippoboscidae (Diptera: Insecta). J Med Entomol 12: 71-76

Kosugi K (2003) About banded gulls. Newsletter Wild Bird Soc Jpn, North Hokkaido Branch 27: 1

Liebers D, de Kniff $P$, Helbig AJ (2004) The herring gull complex is not a ring species. Proc $R$ Soc Lond B 271: 893-901

Maa TC (1969) A revised checklist and concise host index of Hippo- 
boscidae (Diptera). Pac Ins Monog 20: 261-299

Marshall AG (1981) The Ecology of Ectoparasitic Insects. Academic Press, London

Mizukoshi A, Johnson KP, Yoshizawa K (2012) Co-phylogeography and morphological evolution of sika deer lice (Damalinia sika) with their hosts (Cervus nippon). Parasitology 139: 1614-1629

Olsen KM, Larsson H (2004) Gulls of North America, Europe, and Asia. Princeton Univ Press, New Jersey

Pons JM, Hassanin A, Crochet PA (2005) Phylogenetic relationships within the Laridae (Charadriiformes: Aves) inferred from mitochondrial markers. Mol Phylogenet Evol 37: 686-699

Price RD, Hellenthal RA, Palma RL, Johnson KP, Clayton $\mathrm{CH}$ (2003) The Chewing Lice: World Checklist and Biological Overview. Illinois Natural History Survey Special Publication 24, Champaign

SAS Institute Inc (2011) JMP, version 9. SAS Institution, Cray

Shiroyama Y, Kaku T, Higgins RP (1993) Double-sided microscopic observation of meifauna using an HS-slide. Benthos Res 44: 41-44

Smith VS, Page RDM, Johnson KP (2004) Data incongruence and the problem of avian louse phylogeny. Zool Scr 33: 239-259

Swofford DL (2002) PAUP*: Phylogenetic Analysis Using Parsimony (and other methods) 4.0b10. Sinauer Associates, Sunderland

Timmermann G (1951) Die Mövenkneifer. Eine Revision sämtlicher bei echten Möven schmarotzenden Federlinge der Gattung Saemundssonia Tim., 1936. Parasitol News 2: 1-12

Timmermann G (1971) "Regelwidrigkeiten" im Ausbreitungsbild bei Vogelmallophagen (erläutert an den Kletterfederlingen der Watvögel und Möwen). Mitt Hamburg Zool Mus Inst 67: 1351741

Watanuki Y (1988) Regional differences in the diet of Slaty-backed Gulls breeding around Hokkaido. J Yamashina Inst Ornithol 20: 71-81

Weckstein JD (2004) Biogeography explains cophylogenetic patterns in toucan chewing lice. Syst Biol 53: 154-164

Yoshizawa K (2004) Molecular phylogeny of major lineages of Trichadenotecnum and a review of diagnostic morphological characters (Psocoptera: Psocidae). Syst Entomol 29: 383-394

(Received December 16, 2013 / Accepted February 8, 2014) 